Review Article

\title{
Epidemiology of Occupational Asbestos-Related Diseases in China
}

\author{
Shi Xiong CAI ${ }^{1}$, Chao He ZHANG ${ }^{2}$, Xing ZHANG $^{2}$ and Kenji MORINAGA ${ }^{3 *}$ \\ ${ }^{1}$ Institute of Occupational Medicine, Chinese Academy of Preventive Medicine, 29 Nan Wei Road, Beijing 100050, \\ China \\ ${ }^{2}$ Institute of Hygiene, Zhejiang Academy of Medical Sciences, 60 Tian Mu Shan Street, Hangzhou 310013, China \\ ${ }^{3}$ Osaka Medical Center, 1-3-3 Nakamichi, Higashinari-ku, 537-8511, Osaka, Japan
}

Received December 13, 2000 and accepted February 13, 2001

\begin{abstract}
In 1950s and 60s, asbestosis had been a major health hazard for asbestos exposed workers. In the late 1970s, lung cancers with or without asbestosis were found among asbestos workers. All cohort studies on asbestos workers and on chrysotile miners in China showed excess deaths from lung cancer. In a large scale of cohort study on asbestos workers, a synergistic effect was found between cigarette smoking and asbestos exposure in the production of lung cancer. There have been not so many cases of malignant mesotheliomas reported, so far. In the cohort of chrysotile miners, 4 cases of pleural mesothelioma were observed. In the large scale of cohort study on asbestos workers in 9 factories using only chrysotile only one case of pleural mesothelioma was detected for 10 years' observation. In another 2 cohort studies, 2 cases of peritoneal mesotheliomas were found, one in Shanghai asbestos factory where a small amount of crocidolite had been used in 1960s, and one in Anqing asbestos factory that was located near tremolite mine. Further study is needed especially for the relationship between exposure to Chinese chrysotile and malignant mesotheliomas.
\end{abstract}

Kew words: Asbestos-related diseases, Asbestosis, Lung cancer, Pleural plaques, Mesothelioma, Chinese chrysotile

\section{Introduction}

There are many asbestos mines in China. Most of them are chrysotile mines, and mined mainly in Sichuan and Xinkang, Sichuan province, Jinzhou, Liaoning province, Mangai, Qinghai province, Jian, Jilin province and Laiyuan, Hebei province ${ }^{1,2)}$. Asbestos products are the necessities of industrialization, and there are many asbestos factories in China. Between 1960s and early 80s, asbestos spinning process had also been done in household industries. So, a lot of peoples had been occupationally exposed to asbestos in China, and asbestos-related diseases have recently increased. Some important papers were presented at the

\footnotetext{
*To whom correspondence should be addressed.
}

National Conference on Labor Hygiene and Occupational Diseases. Therefore, we included these abstracts in this review of the epidemiological studies on asbestosis, lung cancer, malignant mesotheliomas, and pleural plaques in China.

\section{Asbestosis}

According to the National Pneumoconiosis Survey, 4,289 cases of asbestosis had occurred between 1949 and $1986^{3)}$. A total of 2,503 (58.4\%) cases were found during 1980 to 1986.

The first case of asbestosis in China was found in 1954, and reported at the first National Conference on Labor 
Table 1. Prevalence of asbestosis (1960 1999)

\begin{tabular}{|c|c|c|c|c|c|}
\hline Study (year) & City / Province & $\begin{array}{c}\text { No. of } \\
\text { workers }\end{array}$ & $\begin{array}{c}\text { No. of } \\
\text { asbestosis }\end{array}$ & $\begin{array}{c}\text { Prevalence } \\
(\%)\end{array}$ & Reference \\
\hline \multicolumn{6}{|l|}{ Factories } \\
\hline Shanghai's study (1960) & Shanghai & 352 & 63 & (17.9) & 4 \\
\hline Tianjin's study (1960) & Tianjin & 246 & 60 & $(24.4)$ & 5 \\
\hline Sichuan Medical College's study (1960) & Sichuan & 580 & 111 & $(19.1)$ & 6,7 \\
\hline Liu Hui-zhen, et al. (1979) & Qingdao & 780 & 36 & $(4.6)$ & 9 \\
\hline Lu Pei-lian, et al. (1982) & Shanghai & 1015 & 203 & $(20.0)$ & 10 \\
\hline Ma Bao-jun, et al. (1983) & Haerbin & 205 & 10 & $(4.9)$ & 11 \\
\hline Hu Jian-ping, et al. (1983) & Wu/Jiangsu & 278 & 57 & $(20.5)$ & 12 \\
\hline Huang Jian-quan, et al. (1987) & Suzhou & 269 & 21 & (7.8) & 13 \\
\hline Jia Yu-shan (1988) & Yanbei & 204 & 6 & (2.9) & 14 \\
\hline Li Quan-lu, et al. (1988) & Shanghai & 175 & 45 & $(25.7)$ & 15 \\
\hline Xuan Chun-shan, et al. (1993) & Changchun & 1213 & 161 & (13.3) & 16 \\
\hline Wu Zhong-ya, et al. (1993) & Anqing & 411 & 29 & (7.1) & 17 \\
\hline Lu De-cheng (1995) & Jiangyan/Jiangsu & 755 & 34 & $(4.5)$ & 18 \\
\hline Zhou Kai-hui, et al. (1996) & Changchun & 669 & 169 & $(25.3)$ & 19 \\
\hline Xuan Chun-shan, et al. (1999) & Changchun & 1473 & 170 & $(11.5)$ & 20 \\
\hline \multicolumn{6}{|l|}{ Household industries } \\
\hline Liu Hui-zhen, et al. (1979) & Qingdao & 1178 & 180 & $(15.3)$ & 9 \\
\hline Shijiazhuang's study (1983) & Shijiazhuang & 212 & 72 & $(34.0)$ & 21 \\
\hline Qin Xian-xing, et al. (1983) & (unknown) & 224 & 8 & (3.6) & 22 \\
\hline Mao Chao-yun, et al. (1985) & Yuyao/Zhejiang & 1176 & 71 & $(6.0)$ & 23 \\
\hline Ding Xiao-dun, et al. (1985) & Zhejiang & 1886 & 84 & $(4.5)$ & 24 \\
\hline Wu Zhong-ya, et al. (1987) & Anqing & 501 & 25 & $(5.0)$ & 25 \\
\hline \multicolumn{6}{|l|}{ Mines } \\
\hline Sichuan Sanitation's study (1960) & Sichuan & 1052 & 423 & $(40.2)$ & 8 \\
\hline Zou Shi-qu, et al. (1986) & Laiyuan & 1227 & 154 & (12.6) & 26 \\
\hline \multicolumn{6}{|l|}{ Miscellaneous } \\
\hline Li Wen-jun, et al. (1983) & Taiyuan* & 19 & 10 & $(52.6)$ & 27 \\
\hline Huang Pian-pian, et al. (1983) & Guangzhou** & 93 & 1 & $(1.1)$ & 28 \\
\hline
\end{tabular}

*Repair shop of steam locomotive, **Manufacuturing building materials.

Hygiene and Occupational Diseases in $1959^{4-8)}$.

Table 1 shows the summary of the studies on the prevalence of asbestosis among the asbestos-exposed workers between 1960 and 1999 in China.

In 1950s and 60s, high prevalence of this pneumoconiosis was reported. In those days, the working environments were not good for health, and effective personal protective equipments were seldom used. For example, the level of asbestos dust concentration in an asbestos factory located in Tianjin city, ranged from 81.4 to $315.0 \mathrm{mg} / \mathrm{m}^{3}$ in the fiberizing and carding process, and 30.8 to $32.9 \mathrm{mg} / \mathrm{m}^{3}$ in the spinning process ${ }^{5}$. Its level of an asbestos mine in Sichuan province, ranged from 130.0 to $2,983.0 \mathrm{mg} / \mathrm{m}^{3}$ in the mining process, and from 55.5 to $395.4 \mathrm{mg} / \mathrm{m}^{3}$ in the screening process ${ }^{8)}$.

Fiberizing asbestos process had been done in a small workshop and household industry in the suburban of Anqing,
Anhui province, suburban of Shijiazhuang and Wuqing county, Hebei province, Cixi, Yuyao counties in Zhejiang province, and suburban of Qingdao and Dalian cities. A lot of these inhabitants and farmers had been exposed to asbestos. Shijiazhuang Institute of Occupational Medicine reported that the asbestos dust concentration in a household was 59.5 $\mathrm{mg} / \mathrm{m}^{3}$, which was 28.7 times higher than the National standard exposure level ${ }^{21)}$. The working time ranged from 10 to 12 hours. Not only the workers themselves, but also the inhabitants in the home other than the workers had also been exposed to asbestos. Among the 212 female examinees, $72(34.0 \%)$ were found to have the findings of asbestosis (category $1 ; 59$, category $2 ; 13$ ).

As the working conditions improved with the progress of dust control, the prevalence of this disease decreased down after 1980s. The majority of the studies showed its prevalence 
Table 2. Prevalence of lung cancer $(\mathrm{LC})$ in asbestosis

\begin{tabular}{llcrrr}
\hline Study (year) & City / Province & $\begin{array}{c}\text { No. of } \\
\text { Asbestosis }\end{array}$ & $\begin{array}{c}\text { No. of } \\
\text { LC }\end{array}$ & $(\%)$ & Reference \\
\hline $\begin{array}{l}\text { Factories } \\
\text { Wu Zhi-zhong (1979) }\end{array}$ & Changchun & $* 12$ & 2 & $(16.7)$ & 30 \\
Cooperative Study Group (1986) & 9 cities & $* 87$ & 14 & $(16.1)$ & 31 \\
Chen Li-juan, et al. (1988) & Shanghai & $* 53$ & 12 & $(22.6)$ & 32 \\
Zhang Hui-bin, et al. (1991) & Henan & 36 & $* 2$ & $(5.6)$ & 33 \\
Zheng Zhi-ren, et al. (1992) & nationwide & $* * 78$ & 21 & $(26.9)$ & 34 \\
Zhu Hui-lan, et al. (1993) & 8 cities & $* 148$ & 33 & $(22.3)$ & 35 \\
Wu Zhong-ya, et al. (1993) & Anqing & 29 & 1 & $(3.5)$ & 18 \\
Xuan Chun-shan, et al. (1999) & Changchun & $* 60$ & 11 & $(18.3)$ & 20 \\
Mines & & & & & \\
Cooperative Study Group (1986) & 4 provinces & $* 23$ & 4 & $(17.4)$ & 31 \\
Zou Shi-qu, et al. (1986) & Laiyuan/Hebei & 154 & 6 & $(3.9)$ & 27 \\
Wang Zhi-ming, et al. (1991) & Sichuan & 88 & 13 & $(14.8)$ & 36 \\
\hline
\end{tabular}

*death cases, **autopsied cases.

Table 3. Prevalence of pleural plaques (PP) in asbestosis

\begin{tabular}{llcccc}
\hline Study (year) & City / Province & $\begin{array}{c}\text { No. of } \\
\text { Asbestosis }\end{array}$ & $\begin{array}{c}\text { No. of } \\
\text { PP }\end{array}$ & (\%) & Reference \\
\hline Wang Mao-hua, et al. (1979) & Shanghai & 88 & 38 & 43.2 & 38 \\
Gu Lin, et al. (1983) & Suzhou, Zhenjiang, Nanjing & 131 & 76 & 58.0 & 39 \\
Wang Qing-ren, et al. (1983) & Chongqing & 49 & 26 & 53.1 & 40 \\
Yu Xi-ping, et al. (1984) & Henan & 15 & 15 & 100.0 & 41 \\
Wu Zhong-ya, et al. (1993) & Anqing & 38 & 13 & 34.2 & 18 \\
Wang Xin-jun, et al. (1993) & Qingdao & 107 & 50 & 46.7 & 42 \\
\hline
\end{tabular}

were less than $10 \%$. There was a special reason why the prevalence was very high among the workers in a repair shop of steam locomotives. Li Wen-jun et al. described that the repair of the steam locomotives had high exposure to asbestos ${ }^{27}$. Workers removed the asbestos insulations of the boilers, screened, and reused them. Since 1968, a block of used asbestos insulations were crushed, selected and transported to the repair shop. Workers were exposed for 3 to 4 hours everyday. The asbestos dust concentration showed about $100 \mathrm{mg} / \mathrm{m}^{3}$ on average, and reached up to $400 \mathrm{mg} / \mathrm{m}^{3}$. The health survey on these workers in 1982 revealed 10 asbestosis (category 1; 7, category 2;3) among 19 employees.

Recently, Wang Jing et al. showed high prevalence of asbestosis among 429 workers (230 males and 199 females) in a Beijing asbestos factory ${ }^{29}$. One hundred and fifty three workers were diagnosed as category 1 of asbestosis, 23 as category 2 , and 2 as category 3 . Their exposure duration was 26.5 (3-44) years on average, and their mean age at the onset was $61.2(48-84)$ years old.

The main complicated diseases with asbestosis were lung cancer, malignant mesotheliomas, pleural plaques, and pulmonary tuberculosis. The first case of lung cancer with asbestosis was reported in $1978^{30}$. Among 12 death cases of asbestosis in Changchun city, 5 were found to be complicated with 2 lung cancers, 2 liver cancers, and 1 esophageal cancer. The complication rate of lung cancer in asbestosis ranged from 3.5 to $26.9 \%$ (Table 2). The relationship between asbestosis and mesothelioma will be mentioned later.

In 1979, 3 studies on pleural plaques in asbestosis were reported $^{9,37,38)}$. Wang Mao-hua et al. found 38 cases of pleural plaques in 88 asbestosis $^{38)}$. Latent period from the first exposure to the appearance of pleural plaques was 16 years on average, and 32 cases appeared the radiological findings of pleural plaques, then after asbestosis. The complication rate of pleural plaques in asbestosis ranged from 34.2 to $100 \%$ (Table 3).

According to the National Pneumoconiosis Survey, 4,289 cases of asbestosis were found all over the country between 1949 and 1986. The complication rate of pulmonary 
tuberculosis was $8.9 \%$ (category $1 ; 9.2 \%$, category $2 ; 6.6 \%$, category $3 ; 6.5 \%)^{3)}$. Xuan Chun-shan et al. conducted a mortality study on asbestosis between 1948 and $1995^{20)}$. In a Changchun asbestos plant, Chinese and Canadian chrysotile was used as raw materials. Between 1963 and 1995, 1,473 workers were examined for chest X-ray, and 170 cases of asbestosis were found. No case of asbestosis has occurred on workers who had engaged after 1970. Among them, 60 were found to be dead. The leading cause of deaths was asbestosis (12), the second was lung cancer (11), and the third was pulmonary tuberculosis (9).

\section{Lung Cancer}

It was in 1978 that 3 cases of lung cancer among asbestos workers for 27 years' observation in Qingdao city were reported $^{30)}$. The duration of their exposure to asbestos was 3, 8, and 17 years respectively. The next year, Wang Minggui et al. found 3 autopsied cases of lung cancer among 4 asbestos workers who had not been diagnosed as clinical asbestosis before their deaths ${ }^{41}$. Zhang Zhi et al. reported the details on 11 cases of lung cancer in Chongqing asbestos factory ${ }^{44)}$. Ten cases were males, who were all smokers, and one was female who was never smoker. Among 11 cases, only 4 cases had been diagnosed as category 1 of asbestosis radiologically before their death from lung cancer. Li Jing-xian et al. analyzed 59 lung cancer cases (57 males, 2 females) in Jinzhou chrysotile mine ${ }^{45}$. Thirty-seven cases $(61.7 \%)$ were found in the central, and $22(37.3 \%)$ were in peripheral. The mean death age was 70 years old. Cooperative Study Group on Asbestos-related Occupational Cancer collected and analyzed 134 cases of lung cancer in asbestos exposed workers ${ }^{46}$. Eighty-nine cases (68 males, 21 females) were factory workers and 45 were miners (males only). Histological subgroups of 41 lung cancers were 16 squamous cell carcinoma, 12 undifferenciated carcinoma, 9 adenocarcinoma, one alveolar cell carcinoma, and 3 mesothelioma. The latency from the first asbestos exposure to the appearance of lung cancer (including mesotheliomas) was 23.9 years for factory workers and 25.4 years for miners. The mean age at the diagnosis was 56.6 (males 58.4, females $51.0)$ and 57.3 respectively.

\section{Malignant Mesotheliomas}

In 1979, Zhang Zhi et al. reported an autopsied case of malignant pleural mesothelioma with category 1 of asbestosis $^{47,48)}$. He had been working in an asbestos factory for 14 years and in an asbestos slate industry for 8 years.
In Laiyuan chrysotile mine, 4 workers were suspected to have mesotheliomas based on chest X-ray findings ${ }^{49}$. Among them, one case was ascertained based on the pathological examination after his death. Zou Shi-qu et al. reported three cases of these malignancies among Laiyuan asbestos miners in their cohort ${ }^{26}$. Including these three cases, Cooperative Study Group on Asbestos-related Occupational Cancer collected 7 cases ( 6 males, 1 female) of mesotheliomas in asbestos exposed workers ${ }^{46}$. Their mean exposure duration was 21.3 years, and mean latent period was 28.8 years.

Zhen Zhi-ren et al. reported 7 cases of malignant mesotheliomas ( 6 pleura, 1 peritoneal) among 78 autopsied cases with asbestosis ${ }^{34)}$.

It was in 1993 that Wu Zhong-ya et al. reported the first case of malignant peritoneal mesothelioma among 411 workers in an Anqing asbestos factory ${ }^{17}$. He had been working for 24 years. Pathological examination was done and asbestos was detected in his peritoneum as $20.7 \times 10^{6}$ fibers/g tissue by JC Wagner. Mainly chrysotile was found, but a small amount of tremolite was also detected. There was a tremolite mine near Anqing city, Anhui province, and this factory might use this type of asbestos ${ }^{50)}$.

\section{Pleural Plaques}

Wang Ming-gui et al. reported 7 autopsied cases of asbestos workers ${ }^{51}$. Before their death, only one case was diagnosed as category 1 of asbestosis, and other 6 were not diagnosed as asbestosis, but 5 were found to have pleural plaques based on the chest X-ray. Autopsy revealed all cases had pleural plaques. Yu Xi-ping et al. reported 285 cases of pleural plaques among 956 workers in 8 asbestos factories who had been working for more than one year ${ }^{41)}$. Sun Tong-da et al. examined the chest X-ray on 126 workers and their 185 families in household industries and found 3 cases of pleural plaques ( 2 among workers and one among their family $)^{52}$. The concentration of asbestos fiber was measured in the working environment, dining room, and bedroom. It ranged from 0.039 fiber/cc to $0.83,0.014$ to 0.366 , and 0.01 to 0.65 , respectively. Dong Yun et al. reported 33 cases with pleural plaques among 518 foundry workers ${ }^{53}$. Chrysotile asbestos cloth was used for coremaking. At the demolition of core box, sand was contaminated with asbestos. Sand was reused several times, so the working environment was also contaminated with asbestos. The average working period was 30.8 years ranging 22 to 42 . Wang Zhi-da et al. also reported 32 cases with pleural plaques among another 238 foundry workers ${ }^{54)}$. The prevalence of pleural plaques among asbestos workers ranged from 1.3 to $29.8 \%$ (Table 4). 
Table 4. Prevalence of pleural plaques (PP) among asbestos workers

\begin{tabular}{llrrrr}
\hline \multirow{2}{*}{ Study (year) } & City / Province & $\begin{array}{c}\text { No. of } \\
\text { Workers }\end{array}$ & $\begin{array}{c}\text { No. of } \\
\text { PP }\end{array}$ & (\%) & Reference \\
\hline Yu Xi-ping, et al. (1984) & Henan & 956 & 285 & 29.8 & 41 \\
Sun Tong-da, et al. (1992) & Cixi & $* 311$ & 4 & 1.3 & 52 \\
Dong Yan, et al. (1996) & Shenyang & $* * 518$ & 33 & 6.4 & 53 \\
Wang Zhi-da, et al. (1996) & Shenyang & $* * 238$ & 32 & 13.4 & 54 \\
Morinaga K, Zhang Xing (1998) & Cixi & $* 795$ & 10 & 1.3 & 55 \\
Wang Jing, et al. (199) & Beijing & 429 & 127 & 29.6 & 21 \\
\hline
\end{tabular}

*Hand-spun workers, ${ }^{* *}$ Foundry workers.

\section{Cohort Studies}

In 1982, national project team started to conduct a nationwide retrospective cohort study on 9,950 asbestos workers in 9 factories and 6,198 miners in 5 asbestos mines $^{31,56-58)}$. Nine asbestos factories were located in Beijing, Tianjin, Chongqing, Shenyang, Qingdao, Changchun, Haerbin, Mudanjiang, and Shangqiu. A total of 10,095 workers who had been engaged for more than one year, was selected and 9,950 subjects were ascertained for follow-up. The lost of follow-up was $1.4 \%$. Total person-years were 34,587 for males and 27,754 for females. From the beginning of January 1972 to the end of 1981, 326 (males 260, females 66) were found to be dead. As for lung cancer, 32 were males and 10 were females. Lung cancer SMR was 2.78 for males and 4.79 for females based on the large cities' cancer mortality statistics (1973-1975). Only one male case of pleural mesothelioma was found in Chongqing factory ${ }^{31,58)}$.

Five asbestos mines were located in Chaoyang, Laiyuan, Jinzhou, Xinkang, and Sichuan ${ }^{56)}$. These were all chrysotile mines. All miners who had been engaged for more than one year were ascertained and 6,198 were followed up for the same 10 years. Total person-years were 35,738 for males and 4,558 for females. Only $0.85 \%$ (51) was lost of followup, and 253 (males 240, females 13) deaths were found. The number of lung cancer death was 21 for males and 2 for females. Lung cancer SMR for males was 3.46 based on the national cancer mortality statistics (1973-1975). Three cases were attributed as cause of death from malignant pleural mesotheliomas. All cases had been working in Laiyuan chrysotile mine and not in any other mines ${ }^{26,31,43,56,58)}$. Further 5 years' follow-up study revealed one case of mesothelioma in Sichuan chrysotile mine ${ }^{36}$.

The prospective cohort study on workers in 8 factories was extended for 5 years and the results were published in English elsewhere ${ }^{35}$. Their data also showed a synergistic effect between asbestos exposure and cigarette smoking in the production of lung cancer. A total of 160 male and 370 female workers in Qingdao were followed up till the end of $1994^{62,63)}$. Among 113 deaths, 9 (3 males, 6 females) were lung cancers. Its SMR was 5.09 for males, 6.82 for females. Among 9 cases of lung cancer, 4 were smokers and 5 were non-smokers. Malignant mesothelioma was not yet found. Follow-up on the asbestos workers at two factories in Sichuan was extended up to the end of 1998 and 22 lung cancer deaths were found, but no mesothelioma was found ${ }^{66}$. Table 5 shows the summary of the cohort studies on asbestos exposed workers in China.

Apart from the Cooperative Study, Zhang Hui-bin et al. studied a retrospective cohort survey on 323 asbestos workers for at least one year in two Henan factories ${ }^{33)}$. Their main products were powder, yarn, cord, paper, and cloth of asbestos. Raw asbestos used was chrysotile from Sichuan and Qinghai provinces. The concentration of asbestos dust in the working environment had been up to $18.5-35.8 \mathrm{mg} /$ $\mathrm{m}^{3}$ before 1989. From 1972 to $1988,98.5 \%$ was followedup, and 18 deaths were found. SMR for all cancer (12 deaths) was 1.12 and for lung cancer was 20.97 (5 deaths) compared with the local general population.

Zhou Kai-hui et al. observed 123 deaths among 669 asbestos workers (457 males, 212 females) in a Changchun factory from 1972 to $1995^{19}$. L Lung cancer SMR was 2.39 (21 deaths) for males and 1.78 (3 deaths) for females. Expected death from lung cancer was calculated based on the Changchun general population in 1995 . No case of mesothelioma was found yet.

A mortality study was carried out among asbestos workers in a Shenyang asbestos material ${ }^{65)}$. The cohort included 528 male and 349 female workers and followed between 1972 and 1996. Significant excess were observed for all cancers, lung cancer, ischemic heart diseases, and pneumoconiosis in male workers. Lung cancer SMR for males was 2.13 (95\%CI: 1.38-3.14). Expected number was calculated based on the Shenyan city's mortality statistics. This data suggests 
Table 5. Cohort studies of asbestos exposed workers in China

\begin{tabular}{|c|c|c|c|c|c|c|c|c|}
\hline \multirow{2}{*}{ Study (year) } & \multicolumn{2}{|c|}{ Observation } & \multirow{2}{*}{$\begin{array}{c}\text { No. of } \\
\text { Subjects }\end{array}$} & \multicolumn{3}{|c|}{ Lung Cancer } & \multirow{2}{*}{$\frac{\text { Mesothelioma }}{\text { No. of death }}$} & \multirow{2}{*}{ Reference } \\
\hline & Period & Area & & No. & SMR & $\overline{(\mathrm{RR})}$ & & \\
\hline \multicolumn{9}{|l|}{ Factories } \\
\hline Cooperative Study Group $(1986,96)$ & $1972-81$ & 9 cities & 9950 & 42 & 6.33 & & 1 & 31,58 \\
\hline \multirow[t]{2}{*}{ Chen Li-juan, et al. (1988) } & $1958-85$ & Shanghai\# & M:275 & 14 & 2.28 & & 0 & 62 \\
\hline & & & $\mathrm{F}: 269$ & 4 & 1.74 & & 1 & \\
\hline \multirow{2}{*}{ Wang Zhi-hong, et al. (2000) } & 1959-98 & Shanghai\# & M:275 & 34 & & (7.7) & 1 & 63 \\
\hline & & & $\mathrm{F}: 269$ & 4 & & (2.6) & 1 & \\
\hline Zhang Hui-bin, et al. (1991) & $1972-88$ & Henan & 323 & 5 & 20.97 & & NA & 64 \\
\hline Zhu Hui-lan, Wang Zhi-ming (1993) & 1972-86 & 8 cities & 5893 & 67 & & $(4.2)$ & NA & 35 \\
\hline \multirow[t]{2}{*}{ Zhou Kai-hui, et al. (1996) } & 1972-95 & Changchun & M:457 & 21 & 2.39 & & 0 & 19 \\
\hline & & & $\mathrm{F}: 212$ & 3 & 1.78 & & 0 & \\
\hline \multirow[t]{2}{*}{ Zhang Zhong-qun, et al. (1997) } & 1972-94 & Qingdao & M:160 & 3 & 5.09 & & 0 & 62,63 \\
\hline & & & $\mathrm{F}: 370$ & 6 & 6.82 & & 0 & \\
\hline Takahashi K, et al. (1998) & 1972-96 & Shenyuan & 877 & 25 & 2.13 & & NA & 65 \\
\hline Wang Zhi-ming, et al. (1999) & 1972-98 & Sichuan & M:515 & 22 & 6.52 & & NA & 66 \\
\hline \multicolumn{9}{|l|}{ Mines } \\
\hline Cooperative Study Group $(1986,96)$ & $1972-81$ & 4 provinces & 6198 & $* 21$ & $* 3.46$ & & 3 & 31,58 \\
\hline Qi Yong-gui, et al. (1988) & $1972-81$ & Chaoyang & 806 & 7 & 3.33 & & 0 & 37 \\
\hline Wang Zhi-ming, et al. (1991) & $1972-87$ & Sichuan & 1470 & 13 & 5.72 & & 1 & 36 \\
\hline
\end{tabular}

M: Males, F: Females, RR: Relative Risk, NA: Not Available. *Males only, \# the same cohort.

that smoking and asbestosis have an additive effect on lung cancer mortality. The risk of lung cancer for females was also elevated, but not statistically significant (figure not shown).

Chen Li-juan et al. and Wang Zhi-hong et al. conducted a retrospective cohort study on 551 Shanghai asbestos workers $^{62,63)}$. Only $1.2 \%$ (7 workers) of the cohort was lost to follow-up. A total of 108 ( 79 males, 29 females) cancer cases were observed among 544 subjects ( 275 males, 269 females) between 1959 and 1998. Relative risk of lung cancer for males was 7.7 (34) and 2.6 (4) for females based on the cancer incidence of Shanghai between 1972 and 1994. One male case of peritoneal mesothelioma and one female case of pleural mesothelioma were found among this cohort. In 1960s, a small amount of crocidolite had been used here.

\section{Conclusion}

In China, chrysotile has been mined and used widely. In 1950s and 60s, asbestosis had been a major health hazard for asbestos exposed workers. As the working conditions improved with the progress of dust control, the prevalence of this disease decreased after 1980s. In 1978, the first case of lung cancer with asbestosis was reported in China. A national project team started to conduct a large scale of retrospective cohort study on asbestos workers in 9 asbestos factories and on chrysotile miners in 5 mines who had worked for at least one year. Excess deaths from lung cancer were demonstrated in both asbestos workers and miners. A synergistic effect was observed between cigarette smoking and asbestos exposure in respect to risk of lung cancer. Further 5 years' follow-up study on asbestos workers who had engaged in 8 of 9 above factories and all other cohort studies on asbestos exposed workers in China showed excess risk of lung cancer. It is noteworthy that female asbestos workers had also high risk of lung cancer, because the percentage of smokers in Chinese female workers is low (less than $10 \%)^{57)}$.

There have been not so many cases of malignant mesotheliomas reported, so far. In the large scale of 9,950 asbestos workers in 9 cities for 10 years' observation, only one case of pleural mesothelioma was detected. In the cohort of miners in 5 chrysotile mines, 3 cases of pleural mesotheliomas were observed for 10 years' observation, but these were only in 1,227 Laiyuan miners. One case of pleural mesothelioma was found in 1,470 Sichuan chrysotile miners during 15 years' observation. Two cases of peritoneal mesotheliomas were reported, one in Shanghai factory, and one in Anqing factory. Shanghai asbestos factory had been used a small amount of crocidolite in 1960s. Anqing asbestos factory was located near tremolite mine. Amphibole asbestos was also mined in China, and these types of asbestos had 
been used in local area.

At present, there are no Mesotheliomas Panels in China. Pathological examination, especially postmortem, on the diagnosis of cancer had not so well done in China, and there might be missing the chance of diagnosing this rare malignancy ${ }^{67,68)}$. But with the development of the economics, this procedure has been done more frequently nowadays. Further research is needed especially for mesotheliomas, because most of asbestos mined and used in China is chrysotile.

\section{References}

1) Lu Z, Zhu S (1987) Chrysotile asbestos, In: Industrial minerals and rocks in China. ed. by Tao W, Vol. 1, 35482, Xin-Hua Press, Beijing.

2) Zhu Z, Fan L, Liang W (1986) A study on several kinds of asbestos minerals in China. Minerals Rocks 6 (4), 1-67.

3) Ministry of Health, P.R. China (1992) Data on the national epidemiological investigation of pneumoconiosis (1949-1986), 10-32, Combined Press of Beijing Medical University and Peking Union Medical College, Beijing.

4) Shanghai Institute of Occupational Health, Jiangning District Hospital (1960) A survey of asbestosis in a Shanghai asbestos industry. Abstracts of the 1st National Conference on Labor Hygiene and Occupational Diseases, 337-9, People's Health Press, Beijing.

5) The Second Tianjin Tuberculosis Hospital (1960) Prevalence of asbestosis in a Tianjin asbestos factory. Abstracts of 1st National Conference on Labor Hygiene and Occupational Diseases, 340, People's Health Press, Beijing.

6) Sichuan Medical College (1960) Chest X-ray survey of asbestosis. Abstracts of 1st National Conference on Labor Hygiene and Occupational Diseases, 363, People's Health Press, Beijing.

7) Sichuan Medical College (1960) Survey of asbestosis in an asbestos factory in Sichuan province. Abstracts of 1st National Conference on Labor Hygiene and Occupational Diseases, 341, People's Health Press, Beijing.

8) Sichuan Sanitation and Antiepidemic Station (1960) A survey of asbestosis in an asbestos mine. Abstracts of 1st National Conference on Labor Hygiene and Occupational Diseases, 341-2, People's Health Press, Beijing.

9) Liu H, Lu Y, Zhang G, Wang X, Cao L (1979) An analysis of 216 cases with asbestosis. Abstracts of 2nd National Conference on Labor Hygiene and Occupational Diseases, 183, Society of Occupational Medicine, China Medical Association, Changsha.

10) Lu P, Zhang Z, Wu M, Shi S, Gong Z, Chen T, Lu Z (1982) Asbestosis in a factory of Shanghai. Chin J Prev Med 16, 163-5.

11) Ma B (1983) Survey of asbestosis in a Haerbin asbestos factory. Abstracts of 3rd National Conference of Labor Hygiene and Occupational Diseases, 32, China Medical Association, Hangzhou.

12) Hu J, Ji K, Jiang G (1983) Dose-response relationship between asbestos exposure and asbestosis. Abstracts of 3rd National Conference on Labor Hygiene and Occupational Diseases, 33, China Medical Association, Hangzhou.

13) Huang J, Jiang D, Chen Z, Fei H, Zhuang S (1987) Dose-response study on workers expose to chrysotile in an asbestos paper mill. Chin J Ind Hyg Occup Dis 5, 44-7.

14) Jia Y (1988) A retrospective cohort study of asbestos workers with special reference to asbestosis and cancer. Abstracts of 4th National Conference on Labor Hygiene and Occupational Diseases, 63-4, China Preventive Medical Association, Tianjin.

15) Li Q, Zhang S, Hu T, Guo J (1988) Study on asbestosis among 175 employees with long working age engaging to asbestos. J Labour Med 5, 1-3.

16) Xuan C, Xu C, Wang W, Yang W (1993) Evaluation of the prevention of asbestosis and its prediction. Abstracts of 5 th National Conference on Labor Hygiene and Occupational Diseases, 95, China Preventive Medical Association, Wuhan.

17) Wu Z, Jiang L, Chen B, Bao J (1993) Investigation of occupational hazards in chrysotile asbestos processing. Ind Health Occup Dis 19, 96-7.

18) Lu D (1995) Observation of pleural changes induced by asbestos exposure.Chin J Ind Hyg Occup Dis $\mathbf{1 3}$ (4), 231-2.

19) Zhou K, Liu P, Xuan C, Zhao Y (1996) 24 years followup study on cancer mortality on asbestos workers. China Public Health 12, 515-6.

20) Xuan $C$, Zhao Y, Yang W, Wang Z, Ma X, Ren X, Sun J (1999) Epidemiological survey of asbestosis in an asbestos factory. Chin J Ind Med 12, 45-7.

21) Shijiazhuang Institute of Preventive Occupational Diseases (1983) Asbestosis among hand-spun workers in Shijiazhuang. Abstracts of 3rd National Conference on Labor Hygiene and Occupational Diseases, 34-5, 
China Medical Association, Hangzhou.

22) Qin X (1983) Asbestosis among farmers. Abstracts of 3rd National Conference on Labor Hygiene and Occupational Diseases, 35, China Medical Association, Hangzhou.

23) Mao C, Xu W, Chen Z (1985) Asbestosis among handspun asbestos workers. J Labour Med 2 (4), 1-3.

24) Ding X, Lu S, Ni W (1985) Analysis of chest X-ray findings on 1886 asbestos workers. J Labour Med 2 (4), 11-2.

25) Wu Z, Liu B, Yang S, Li B, Bao J, Li X, Li X, Wang X, Wang H (1987) Prevalence of asbestosis among women worker in rural asbestos textile mill. Occup Med 14 (2), 7-8.

26) Zou S, Ma F, Song W, Wu Y, Ma H, Jiang Z (1986) Retrospective mortality cohort study of asbestos workers in Laiyuan. Chin J Ind Hyg Occup Dis 4, 264-7.

27) Li W, Guo Z, Dong B, Qin G (1983) Health hazard of reuse of asbestos in steam locomotives. Abstracts of 3rd National Conference on Labor Hygiene and Occupational Diseases, 32, China Medical Association, Hangzhou.

28) Huang P, Shen L, Weng Q, Zhu Y, Qi Y (1983) Survey of health hazards on asbestos workers. Abstracts of 3rd National Conference on Labor Hygiene and Occupational Diseases, 33-4, China Medical Association, Hangzhou.

29) Wang J, Liu M, Cheng Y (1999) Analysis of chest Xray findings among 429 asbestos workers. Chin Occup Med 26 (4), 42-3.

30) $\mathrm{Wu} \mathrm{Z} \mathrm{(1979)} \mathrm{The} \mathrm{retrospectives} \mathrm{and} \mathrm{prospectives} \mathrm{of}$ 30 years' prevention and research on pneumoconiosis. Abstracts of 2nd National Conference on Labor Hygiene and Occupational Diseases, 5-10, Society of Occupational Medicine, China Medical Association, Changsha.

31) Cooperative Study Group on Asbestos-related Occupational Cancer (1986) Survey of occupational cancer induced by asbestos. Chin J Ind Hyg Occup Dis 4 (4), 216-8.

32) Chen L, Li Q, Hu T, Guo J (1988) Historical prospective study on the experience of malignant tumor in Shanghai asbestos factory. J Labour Med 5 (1), 6-8.

33) Zhang H, Cheng G, Li L, Xue S, Zhang W (1991) Follow-up study for 17 years on the malignant tumors among the workers exposed to chrysotile. In: Archives of the China-Japan Medical Exchange in 1991, 99103, China Preventive Medical Association \& JapanChina Medical Association, Tangshan.
34) Zheng Z, Liang S (1992) Pathological study on lung cancer with pneumoconiosis. Chin J Ind Hyg Occup Dis 10, 257-60.

35) Zhu H, Wang Z (1993) Study of occupational lung cancer in asbestos factories in China. Br J Ind Med 50, 1039-42.

36) Wang Z, Wang M, Liu X, Luo S (1991) An investigation on asbestos induced malignant tumour. Ind Health Occup Dis 17, 144-52.

37) Chen C, Wang Y (1979) Study on the changes of chest $\mathrm{X}$-ray findings and the diagnosis of staging for asbestosis. Abstracts of 2nd National Conference on Labor Hygiene and Occupational Diseases, 184, Society of Occupational Medicine, China Medical Association, Changsha.

38) Wang M, Jing H (1979) The value of pleural plaques in the diagnosis for asbestosis. Abstracts of 2nd National Conference on Labor Hygiene and Occupational Diseases, 185, Society of Occupational Medicine, China Medical Association, Changsha.

39) Gu L, Ha K, Ji Y, Zhou J (1983) Chest X-ray finding of asbestosis. Abstracts of 3rd National Conference on Labor Hygiene and Occupational Diseases, 98-9, China Medical Association, Hangzhou.

40) Wang Q, Liu M, Wang J, Zhang Z (1983) A study on pleural plaques in asbestos workers. Abstracts of 3rd National Conference on Labor Hygiene and Occupational Diseases, 101-2, China Medical Association, Hangzhou.

41) Yu X, Zhang H (1984) A chest study of asbestos workers. Chin J Prev Med 18, 42-4.

42) Wang X, Dou Z, Wu X (1993) Pleural changes in asbestosis. Abstracts of 5th National Conference on Labor Hygiene and Occupational Diseases, 104, China Preventive Medical Association, Wuhan.

43) Wang M, Jin S, Zhang L, Zhao Y (1979) Pathological report on 4 cases with asbestosis. Abstracts of 2nd National Conference on Labor Hygiene and Occupational Diseases, 186-7, Society of Occupational Medicine, China Medical Association, Changsha.

44) Zhang Z, Jiang X, Cheng D, Liu B, Wang J, Liu M (1984). An analysis of 11 cases of bronchogenic carcinoma in asbestos workers. Chongqing Yixueyuan Xuebao 9, 181-4.

45) Li J, Xie G (1995). A retrospective analysis of 59 cases with lung cancer in an asbestos miners. J Ind Med 8, 301-2.

46) Cooperative Study Group on Asbestos-related Occupational Cancer (1993) Analysis of 134 lung 
cancer cases among asbestos workers. Chin J Ind Hyg Occup Dis 11, 291-2.

47) Zhang Z, Liu M, Wang J (1979) Pleural mesotheliomas and asbestos exposure. Abstracts of 2nd National Conference on Labor Hygiene and Occupational Diseases, 185-6, Society of Occupational Medicine, China Medical Association, Changsha.

48) Zhang Z, Liu M, Wang J (1980) Pleural mesotheliomas and asbestos exposure. Chin J Tub Respir Dis 3, 52-4.

49) Baoding District Sanitaion and Antiepidemic Station (1979) Diffuse pleural mesotheliomas due to chrysotile. (Survey of pleural mesothelioma in Laiyuan asbestos mine). Abstracts of 2nd National Conference on Labor Hygiene and Occupational Diseases, 187-8, Society of Occupational Medicine, China Medical Association, Changsha.

50) Lu Z, Zhu S (1987) Amphibole Asbestos, In: Industrial Minerals and Rocks in China. ed. by Tao W, Vol. 2, 99-136, XinHua Press, Beijing.

51) Wang M, Zhang L, Liu J, Zhang $X$, Ma $X$, Zhang $T$ (1984) Pathological study of pleural plaques in 7 autopsy cases of asbestos workers. Chin J Prev Med 18, 288-9.

52) Sun $T$, Nie G, Qin F, Tian N, Ding $X$, Zhang C, Cao X, Hu R (1992) Hazard research on asbestos during handspinning in rural home-industry. J Labour Med 9 (3), $1-2$.

53) Dong Y, Ding E, Ma L, Li Y, Yan B, Chen L, Xu G, Li $X$ (1996) A survey of health hazards on foundry workers due to the exposure to asbestos. Chin J Ind Med 9, 227 8.

54) Wang Z (1996) A survey of asbestos health hazards in a foundry work. Chin J Ind Med 9, 303.

55) Morinaga K, Zhang X (1998) A health survey on asbestos exposed ex-workers in Ningbo, Zhejiang province. NitchuIgaku 13 (3), 14.

56) Zhu H, Wang Z (1987) Retrospective cohort study on the workers exposed to chrysotile. Chin J Ind Hyg Occup Dis 5, 29-32.

57) Zhu H, Yang G, Wang F, Liu Q, Wang L (1993) Survey of smoking status in asbestos workers. Ind Health Occup Dis 19 (1), 24-5.

58) Zhu H, Wang Z (1996) An epidemiological study of cancer mortality on asbestos workers. Data of the Epidemiological Study on Occcupational Cancer in China (1982-1984), 26-43, Ministry of Health, P.R.China, Beijing.

59) Zou S, Wu Y, Ma F, Ma H, Sueng W, Jiang Z (1990) Retrospective mortality study of asbestos workers in Laiyuan. Proceedings of 7 th International Pneumoconiosis Conference, DHSS (NIOSH) Publication N. 90-108, Part 2, 1242-4.

60) Qi Y, Xiao X, Wei Z, Han G, Xing C, Wei S, Li J, Zhao L (1988). A retrospective cohort study of asbestos workers. Chaoyang Yiyao (1), 4-8.

61) Wang Z, Cao Y, Wang M, Wang J, Yang H, Zhang K, Duan-mu B (1988) Asbestos and lung cancer, Chin J Ind Hyg Occup Dis 6, 6-8.

62) Zhang Z, Zhang H, Wang Y (1997) A retrospective mortality study of malignant neoplasms among asbestos exposed workers. Chin J Ind Med 10, 35-7.

63) Pang Z, Zhang Z, Wang Y, Zhang H (1997) Mortality from a Chinese asbestos plant: Overall cancer mortality. Am J Ind Med 32, 442-4.

64) Wang Z, Hu Y, Guo J (2000) Study on incidence of malignant tumor in workers of Shanghai asbestos products factory in 40 years. J Labour Med 17, 91-5.

65) Takahashi K, Pan G, Feng Y, Hanaoka T, Hoshuyama T, Okubo T (1998) Cohort study of mortality risk in a Chinese asbestos materal plant. In: Advances in the Prevention of Occupational Respiratory Diseases, 31821, Elsevier, Amsterdum.

66) Wang Z, Wang M, Lan Y (1999) Chrysotile and malignant tumor-A fixed cohort study. Abstracts of the first China-Japan Joint Asbestos Symposium, 27, Institute of Occupational Medicine, APM \& Japan Asbestos Hazards Study Group, Beijing.

67) Office of Prevention and Cure Research for Cancer, Ministry of Health, China, ed. (1980) National Survey on Cancer Mortality in China, 1-7, People's Health Press, Beijing.

68) McLaughlin JK, Chen J, Dosemeci M, Chen R, Rexing SH, Wu Zhen, Hearl FJ, McCawley MA, Blot WJ (1992) A nested case-control study of lung cancer among silica exposed workers in China. Br J Ind Med 49, 167-71. 